\title{
Malformación anorrectal neonatal asociada a bradicardia sinusal
}

\author{
Coria A. ${ }^{1}$, Martínez G. ${ }^{2}$, Membrives C. ${ }^{2}$ \\ 1 Hospital Lagomaggiore, Mendoza, Argentina. \\ 2 Hospital Notti, Mendoza, Argentina.
}

Introducción: Las malformaciones anorrectales (M.A.R.) presentan una frecuencia de 1/5.000 nacidos vivos. Pudiendo ser defectos de nacimiento congénitos aislados o como parte de un síndrome.

Las anomalías asociadas están presentes en un 60-70\% de los casos, siendo las más graves las urológicas y/o cardíacas.

Los trastornos del ritmo en la época neonatal son muy frecuentes y comprenden un espectro clínico variado, generalmente benigno.

Caso clínico: Paciente de 4 días de edad, grande para edad gestacional con M.A.R. baja con fístula a escroto, micropene probable y cefalohematoma frontal.

Examen físico: soplo funcional, grado 3/6 ,mesosistólico. E.C.G: bradicardia fetal 75 lpm. Presentó 2 episodios de hipoglucemia.

Ante dichos hallazgos se solicita ecocardiograma informado, que muestra no asociación con cardiopatía estructural; se prepara quirófano contando con la disponibilidad de drogas vasoactivas. Se coloca monitorización no invasiva y estetoscopio esofágico, se realiza inducción con sevofluorano y fentanilo $2 \mathrm{mcg} / \mathrm{kg}$. Se intuba al paciente y se coloca en decúbito ventral. El procedimiento quirúrgico es llevado a cabo sin contratiempos. Dada la estabilidad hemodinámica (FC:130 lpm) se procede a la extubación y traslado a neonatología. Nuevamente se constata FC:70 lpm, se interpreta como bradicardia sinusal.

Información adicional: Hay tres patologías en las cuales tenemos que pensar ante una bradiarritmia en el período neonatal. Bloqueo AV congénito, síndrome de QT largo, y enfermedad del nodo sinusal.

Los bloqueos AV se encuentran relacionados con patología materna (LES, SJÖGREN) suele necesitar seguimiento, utilización de corticoides en casos leves y colocación de marcapasos en bloqueos $\mathrm{AV}$ de $3^{\circ}$ grado.

El síndrome de QT largo congénito, es una de las patologías que causa muerte súbita del lactante.

La enfermedad del nodo sinusal, afecta generalmente a niños con cardiopatía congénita o post-cirugía cardíaca. Suele ser asintomática, siempre debemos descartar otras causas como: hipotiroidismo, hipoglucemias, medicación materna, enfermedades autoinmunes maternas.

El tratamiento en todas estas patologías se debe realizar en base a la funcionalidad cardiaca, puede realizarse con atropina, isoprotenerol, marcapasos transitorio y permanente.

Comentarios y Discusión: Es importante descartar la gran cantidad de malformaciones relacionadas, como diabetes gestacional que incluye agenesia de sacro, o síndrome de VATER entre otras.

Ante un paciente de estas características siempre debemos plantearnos descartar posibles alteraciones estructurales mediante ecocardiograma, incluso holter en algunos casos. La preparación previa con drogas inotrópicas y carro de paro, es esencial para poder resolver futuros eventos desafortunados.

https://doi.org/10.25237/congresoclasa2019.79 